\title{
Growth performance and meat quality of meat-type guinea fowl fed different commercial diets
}

\author{
Justyna Batkowska ${ }^{1}$, Kamil Drabik ${ }^{1}$, Małgorzata Karwowska ${ }^{2}$, Umair Ahsan $^{3}$, Ifrah Raza ${ }^{4}$, \\ Agnieszka Adamczuk ${ }^{5}$, and Beata Horecka ${ }^{1}$ \\ ${ }^{1}$ Institute of Biological Basis of Animal Production, University of Life Sciences in Lublin, \\ 13 Akademicka St., 20-950 Lublin, Poland \\ ${ }^{2}$ Department of Meat Technology and Food Quality, University of Life Sciences in Lublin, \\ 8 Skromna St., 20-704 Lublin, Poland \\ ${ }^{3}$ Department of Plant and Animal Production, School of Food, Agriculture and Livestock, \\ Burdur Mehmet Akif Ersoy University, İstiklal Campus, Burdur 15030, Turkey \\ ${ }^{4}$ Department of Animal Nutrition and Nutritional Diseases, Faculty of Veterinary Medicine, \\ Aydın Adnan Menderes University, Işıklı, Aydın 09016, Turkey \\ ${ }^{5}$ Institute of Agrophysics, Polish Academy of Sciences, 4 Doświadczalna St., 20-290 Lublin, Poland \\ Correspondence: Kamil Drabik (kamil.drabik@up.lublin.pl)
}

Received: 5 January 2021 - Revised: 31 May 2021 - Accepted: 15 June 2021 - Published: 28 July 2021

\begin{abstract}
The aim of study was to assess the growth performance, meat quality, and fatty acid composition of meat-type guinea fowl fed balanced commercial diets under two different feeding programs, similar to those for slaughter turkeys and broiler chickens, respectively. A total of 804 -week-old meat-type guinea fowl divided into two groups (four replicates per group; 10 birds in each replicate) were raised for 14 weeks. One group received commercially available diets in a three-phased program (TM group), whereas the other group was fed commercial diets in a two-phased program (CM group). Growth-performance-related traits were recorded. At the end of rearing (14 weeks of age), eight birds from each group were slaughtered. Carcass yield and technological traits of meat ( $\mathrm{pH}$, color, water-holding capacity, natural and thermal loss, tenderness, fatty acid profile) were analyzed. Groups did not differ in terms of body weight as well as carcass yield and characteristics. There was no difference in meat quality and the fatty acid profile of breast and thigh meat of guinea fowl from TM and $\mathrm{CM}$ groups. The findings of this study suggest that both commercial diets (for broiler chickens and turkeys) can be used in meat-type guinea fowl rearing. Due to the lower price of diets fed to the CM group and the lack of significant variation in meat quality traits, its use seems to be more justified from an economic point of view.
\end{abstract}

\section{Introduction}

Guinea fowl is an indigenous species of African birds, although their adaptability has contributed to the spread of their breeding worldwide (Agwunobi and Ekpenyong, 1990). Variability of phenotypic features, availability of different color varieties (Agbolosu et al., 2014; Panyako et al., 2016), in addition to attractiveness of guinea fowl in terms of appearance, behavior, and obtained raw materials made them very popular among small-scale farmers (Moreki and Seabo, 2012). A recent study showed that guinea fowl is an impor- tant source of animal protein due to their high availability and relatively low market price (Obike et al., 2011).

In general, guinea fowl is used for laying purposes. During the season, the bird lays up to 190 eggs, relatively a higher production that may last for even 2 to 3 years (Gwaza and Elkanah, 2017). There is some diversification in laying characteristics between the bird's varieties (Onunkwo and Okor, 2015); however, guinea fowl eggs are noteworthy for their thick shell, high proportion of yolk (Alkan et al., 2013), high content of vitamins and trace elements (Bashir et al., 2015), and longer, in comparison to chicken eggs, shelf life (Ay- 
orinde, 1991). Eggs are used for both direct consumption and processing (Agbolosu et al., 2014). Guinea fowl meat is described by a darker color and a unique flavor. It has a proper texture that is attributed to its white muscle fibers, which correspond in quantity to the muscles of chickens but in size to those of geese (Bernacki et al., 2012a). Guinea fowls are characterized by relatively higher slaughter performance (Ebegbulem and Asuquo, 2018) good ratios of valuable parts in the carcass as well as satisfactory sensory properties of meat (Kyere et al., 2020). Additionally, the nutritional value of guinea fowl meat distinguishes it from other poultry species due to higher protein and lower fat content (Ayorinde, 1991).

Several factors influence the quality and quantity of meat production of guinea fowl. Baeza et al. (2001) indicated the importance of genotype (variety) of guinea fowl and their sex, while Yamak et al. (2018) also mentioned age and husbandry conditions important as qualities determinant of meat. However, production results of these birds are constantly influenced by the quality and nutritional value of the feed. Under natural conditions, guinea fowl take up a variety of plant and animal feed, which indicates their adaptation to various sources of protein and energy. In countries where guinea fowl are a popular species of meat-type poultry, certain feeding norms are applied (Yildirim, 2012) that allow for the standardization of compound feed. However, in many countries, these birds are treated as an attraction and possibly used to obtain eggs mostly for self-supply of the farm despite being raised frequently on small-scale farms.

The supplying of guinea fowl carcasses is very limited, although consumers declare an interest in them. This may be attributed to no established nutrient requirements of guinea fowl in terms of protein, energy, amino acids, and other micro- and macro-nutrients, as well as there being no commercial balanced feed mixtures for these birds on the market. However, mixtures are widely available for the other meattype birds, varying both in nutritive value and price. Therefore, the aim of this study was to assess the performance and meat quality of meat-type guinea fowls fed with commercial diets under the dedicated phases of feeding programs.

\section{Material and methods}

\subsection{Bird rearing}

According to Polish legislation the Directive 2010/63/EU implemented on the protection of animals used for scientific purposes (European Parliament and the Council of the European Union, 2010), research performed on animal raw material or as normal, production cycle are treated as nonexperimental agricultural practices (Chapter I, article 1, point 5) and does not need ethical committee approval. At the same time, the birds were maintained in accordance with current legislation with regard to environmental conditions and stocking density.
A total of 80 4-week-old meat-type guinea fowl (French commercial set) were divided into two groups, each consisting of four replicates of 10 birds in each replicate. The birds were reared in a deep litter system. One group was fed commercial diets in a three-phased feeding program (TM group, starter 0-6 weeks, grower 7-12 weeks, finisher > 13 weeks of age) similar to that of the slaughter turkeys' feeding program. The second group received commercial diets in a two-phased feeding program (CM group, starter 0-3 weeks, grower $>4$ weeks until slaughter) similarly to that of broiler chickens. The nutritional values of all diets are shown in Table 1 .

\subsection{Meat quality}

All the birds were weighed individually on a weekly basis and feed intake was recorded. Based on this, the feed conversion ratio (FCR) was estimated. At the end of 14th week, eight birds were randomly selected and slaughtered from each group. Birds were subjected to feed restriction $8 \mathrm{~h}$ prior to slaughter. Birds were slaughtered (in a commercial poultry abattoir) by decapitation following electrical stunning using an electric current of $45 \mathrm{~mA}$. The whipping procedure was in line with EU regulation no. 1099/2009 of 24 September 2009 (Council of the European Union, 2009) on the protection of animals at the time of slaughtering. After plucking and evisceration, the carcasses were chilled by air method $\left(0^{\circ} \mathrm{C}, 4 \mathrm{~h}\right)$. Following this, parts of carcasses were extracted during the dissection (Hahn and Spindler, 2002): breast muscles, thighs, drumsticks, wings, and trunk, as well as the left breast and femoral muscles were taken for further analysis. Edible giblets (heart, liver, gizzard) and parts were weighed to assess the organs and part yields.

The evaluation of meat quality included $\mathrm{pH}$ measurement $(15,60 \mathrm{~min}$, and $24 \mathrm{~h}$ after slaughter) with the use of $\mathrm{pH}$ meter CP-251, water-holding capacity according to Grau and Hamm (1953) method, natural drip loss (Lundstrom and Malmfors, 1985), and thermal (cooking) loss (Yang et al., 2006). Cuboid cores $(1 \mathrm{~cm} \times 1 \mathrm{~cm} \times 2 \mathrm{~cm}$ of edge length) were cut from the heat-treated muscles, parallel to the longitudinal orientation of the muscle fibers. Warner-Bratzler shear force was determined using a texture analyzer TA-XT plus (Stable Micro Systems Ltd., Surrey, UK) equipped with a V-shaped blade. Samples were shorn at a crosshead speed of $2 \mathrm{~mm} \mathrm{~s}^{-1}$.

Color parameters (Commision Internationale de l'Eclairage - CIE $L^{*}, a^{*}$, and $b^{*}$ ) were measured twice: on freshly cut muscle surfaces (after carcass cooling) and on heat-treated samples using an X-Rite Color®Premiere 8200 spectrophotometer (X-Rite Inc., Michigan, USA). The thickness of the samples was at least $10 \mathrm{~mm}$. The instrumental conditions were a $25.4 \mathrm{~mm}$ diameter area aperture. The measurement was carried out in the range of $360-740 \mathrm{~nm}$. The illuminant D65 and a $10^{\circ}$ standard colorimetric observer was used as a source of light. A white standard was used as a reference source with a specification 
Table 1. The composition of feed mixture dedicated for turkeys and chickens depending on the birds' age.

\begin{tabular}{|c|c|c|c|c|c|}
\hline \multirow[t]{3}{*}{ Item } & \multicolumn{3}{|c|}{ Three-phased diets (TM group) } & \multicolumn{2}{|c|}{ Two-phased diets (CM group) } \\
\hline & \multicolumn{3}{|c|}{ Age of birds } & \multicolumn{2}{|c|}{ Age of birds } \\
\hline & $0-6$ weeks & $7-12$ weeks & $>13$ weeks & $0-3$ weeks & $>4$ weeks \\
\hline Crude protein $(\%)$ & 24.30 & 19.70 & 15.90 & 19.00 & 17.40 \\
\hline Crude fat $(\%)$ & 4.10 & 4.00 & 3.80 & 3.80 & 5.10 \\
\hline Crude fiber $(\%)$ & 3.20 & 3.50 & 3.60 & 3.70 & 4.10 \\
\hline Crude ash $(\%)$ & 7.10 & 5.60 & 4.50 & 5.30 & 4.40 \\
\hline Lysine $(\%)$ & 1.54 & 1.18 & 0.90 & 1.12 & 1.00 \\
\hline Methionine (\%) & 0.60 & 0.45 & 0.37 & 0.46 & 0.40 \\
\hline Calcium $(\%)$ & 1.30 & 1.00 & 0.80 & 0.90 & 0.60 \\
\hline Phosphorus (\%) & 0.68 & 0.54 & 0.37 & 0.48 & 0.40 \\
\hline Sodium $(\%)$ & 0.16 & 0.14 & 0.15 & 0.16 & 0.16 \\
\hline Selenium $\left(\mathrm{mg} \mathrm{kg}^{-1}\right)$ & 0.70 & 0.40 & 0.30 & 0.30 & 0.30 \\
\hline Iron $\left(\mathrm{mg} \mathrm{kg}^{-1}\right)$ & 88.00 & 48.00 & 40.00 & 40.00 & 34.00 \\
\hline Iodine $\left(\mathrm{mg} \mathrm{kg}^{-1}\right)$ & 2.00 & 1.00 & 1.00 & 1.00 & 1.00 \\
\hline $\operatorname{Zinc}\left(\mathrm{mg} \mathrm{kg}^{-1}\right)$ & 166.00 & 90.00 & 75.00 & 75.00 & 63.00 \\
\hline Manganese $\left(\mathrm{mg} \mathrm{kg}^{-1}\right)$ & 133.00 & 72.00 & 60.00 & 60.00 & 51.00 \\
\hline Copper $\left(\mathrm{mg} \mathrm{kg}^{-1}\right)$ & 33.00 & 18.00 & 15.00 & 15.00 & 13.00 \\
\hline Vitamin A (IU kg $\left.{ }^{-1}\right)$ & 24500.00 & 12000.00 & 10000.00 & 10000.00 & 8500.00 \\
\hline Vitamin E (IU kg $\left.{ }^{-1}\right)$ & $105.00 \mathrm{mg} \mathrm{kg}^{-1}$ & 30.00 & 25.00 & 25.00 & 21.00 \\
\hline Vitamin $\mathrm{D}_{3}\left(\mathrm{IU} \mathrm{kg}^{-1}\right)$ & $6100.00 \mathrm{IU} \mathrm{kg}^{-1}$ & 3100.00 & 3000.00 & 3000.00 & 2500.00 \\
\hline 6-Phytase EC $\left(\mathrm{FTU} \mathrm{kg}^{-1}\right)$ & 1045.00 & 498.00 & 995.00 & 1005.00 & 503.00 \\
\hline Endo-1,4-beta xylanase $\left(\mathrm{U} \mathrm{kg}^{-1}\right)$ & 1592.00 & 1592.00 & 1592.00 & 1608.00 & 2412.00 \\
\hline Monensin sodium/salinomycin $\left(\mathrm{mg} \mathrm{kg}^{-1}\right)^{*}$ & 100.00 & 100.00 & - & 70.00 & 60.00 \\
\hline
\end{tabular}

* Coccidiostat withdrawn $14 \mathrm{~d}$ before slaughter.

of $L^{*}=95.87, a^{*}=-0.49, b^{*}=2.39$. The results were expressed in units of the CIELAB (Commision Internationale de l'Eclairage, 1978) system, for which the distinctions reflect the following, respectively:

- $L^{*}$ - color brightness, generally adopts positive values and can take values from 0 for an extremely black body and to 100 for a perfectly white body;

- $a^{*}$ - chromaticity in the red-green range; it shows red if it is positive, green if it is negative;

$-b^{*}-$ yellow-blue chromaticity; it shows yellow if it is positive, blue if it is negative.

The change of color parameters of samples (before and after heat treating) was calculated according to the equation and interpreted based on scale given below (Clydesdale, 1976):

$\Delta E=\sqrt{(\Delta L)^{2}+(\Delta a)^{2}+(\Delta b)^{2}}$.

The color change scale is as follows:

$-0<\Delta E<1-$ the observer does not see any difference,

$-1<\Delta E<2$ - only an experienced observer can see the difference,
$-2<\Delta E<3.5-$ the difference is also noted by the nonexperienced observer,

$-3.5<\Delta E<5$ - the observer notes a clear color difference, and

$-5<\Delta E-$ the observer gets the impression of two different colors.

\subsection{Fatty acid profile}

The fatty acid profile of breast and thigh meat was analyzed using the gas chromatography according to PN-EN ISO 5508: 1996 and PN-EN ISO 5509: 2001 using a Varian 450-GC gas chromatograph fitted with a flame ionization detector (FID). Injector and detector temperatures were 250 and $300^{\circ} \mathrm{C}$, respectively. After injection, the column temperature was programmed to increase to $200^{\circ} \mathrm{C}$ for $10 \mathrm{~min}$, subsequently increased to $240^{\circ} \mathrm{C}$ at the rate of $3{ }^{\circ} \mathrm{C} \mathrm{min}^{-1}$. Then, the column temperature was held at the final temperature for $4 \mathrm{~min}$. Helium was used as a carrier gas $\left(3 \mathrm{~mL} \mathrm{~min}^{-1}\right)$.

Based on the proportions of particular fatty acids and their groups, the following indexes were calculated: PI - peroxidation index (Arakawa and Sagai, 1986), AI - atherogenic index and TI - thrombogenic index (Ulbricht and 
Southgate, 1991), DFA - desirable fatty acid (Medeiros et al., 2014), HSFA - hypercholesterolaemic saturated fatty acid (Renna et al., 2012), and h / H - hypocholesterolemic / hypercholesterolemic ratio (Domaradzki et al., 2019). Additionally, the average carbon chain length (ACL) was estimated on the base of the number of carbon atoms in the determined fatty acids.

The obtained data were statistically analyzed using the SPSS 24.0 statistical package (IBM Corp., 2016) The groups were compared using a $t$ test.

\section{Results}

\subsection{Growth performance and carcass yield}

Growth-performance-related traits of guinea fowl are presented in Table 2 . The body weight of birds was similar during the whole rearing period regardless of the diets. Slightly better body weight gain was registered in the TM group than the CM group; however, these differences were not confirmed statistically. The feed conversion ratios were also similar in both groups except for period between eighth and ninth weeks, which was considerably greater in the TM group. However, it is impossible to explain this relation logically; it seems rather incidental. At the end of experiment, the TM group had slightly greater body weight. However, from an economic point of view, the difference was not statistically confirmed.

There were no regular relations between groups in the case of feed conversion ratio. Mostly, the group fed the CM diet needed more feed per $1 \mathrm{~kg}$ of body weight gain that was reflected in overall growth period, whereas birds from the TM group utilized less feed per $1 \mathrm{~kg}$ of body weight gain. The difference amounted to $6.26 \%$ and was statistically significant.

Carcass characteristics of guinea fowl are shown in Table 3. Relative carcass and organ yields were not different between the groups although carcass, edible giblets, breast, and thigh yields were numerically better in CM group.

\subsection{Meat quality}

Table 4 details the breast and thigh muscle quality of guinea fowl fed commercial diets under dedicated feeding programs. Technological traits of breast and thigh meat were not affected by different diets. The results were pointed at proper post-mortem glycolysis. Although any differences were not confirmed statistically, it is visible that numerically slightly better traits linked with water-holding capacity or tenderness were characterized in the breast meat birds in CM group. However, breast and thigh muscles of birds from the CM group diet were characterized by lower $L^{*}$ and $a^{*}$ values compared to the TM group.

\subsection{Fatty acid profile}

The fatty acid profile of thigh and breast muscles of guinea fowl fed commercial turkey and broiler diets is presented in Tables 5 and 6. Most of fatty acids were not affected by different diets. Polyunsaturated fatty acids such as $\gamma$ linolenic acid (GLA) and alpha-linolenic acid (ALA) were higher $(P<0.05)$ in breast meat of birds in the TM group; however, meat from the CM group contained numerically more arachidonic acid (AA) in breast meat. In addition, the $\mathrm{CM}$ group had a numerically higher content of polyunsaturated fatty acid (PUFA) in breast meat. At the same time, values of PI were smaller in both muscles, which points towards the longer shelf life of this meat. Other indexes of fatty acid profile were similar between the groups regardless of muscle type. Any diet used did not contribute to an increase in the hypercholesterolemic properties of meat.

\section{Discussion}

The given body weight significantly exceeds the value obtained in the experiment of Khairunnesa et al. (2016) in the 14th week of life of guinea fowls of the pearl variety. The authors described the birds' rearing system as an intensive one and used feed with $21 \%$ protein content. Wallace et al. (2018) reported that the body weight of 18-week-old guinea fowl ranged from 1058 to $1224 \mathrm{~g}$ regardless of the protein source used in the feed (insect larvae vs. fish meal), which was about $50 \%$ of the final body weight obtained in this study. Such a huge difference may be mainly due to the fact that the laying-type variety of guinea fowl was used in addition to nutrient content of diets such as the protein level that remained around $15 \%$. The results obtained in terms of feed intake are more than $1 \mathrm{~kg}$ better (average value for 14 weeks) than those noticed by Bernacki et al. (2012a) regardless of the evaluated color variety of birds. However, it should be considered that the distinguishing trait was the utility type of birds (meat vs. laying) apart from the plumage color. The meat-type guinea fowls were used in the study of Tufarelli et al. (2015) by replacing soybean in the feed mixture with micronized dehydrated lupine. At the age of 12 weeks, they reached a weight of over $1900 \mathrm{~g}$, which corresponds to the guinea fowls of the TM group in this study. Birds fed commercial broiler diets were slightly lighter. The growth curve for meat-type French guinea fowl depending on sex is presented by Nahashon et al. (2006). They reported that the average body weight of 9-week-old male and female birds should be 1312 and $1304 \mathrm{~g}$, respectively. The results obtained for guinea fowls included in our experiment were significantly better despite lower protein content in feed. Baeza et al. (2001) indicated the importance of bird genotype (growth rate), sex, and thermal conditions during rearing for this trait. Females were bigger irrespective of the genotype as well as high productive line of birds kept during the winter period and with a standard growth rate. In this study, the influence 
Table 2. Growth performance of guinea fowl in response to diets based on nutrient specifications for three- or two-phased diets (mean \pm SEM).

\begin{tabular}{|c|c|c|c|c|c|c|c|}
\hline \multirow[t]{2}{*}{ Age (weeks) } & \multicolumn{3}{|c|}{ Body weight (g) } & \multirow[t]{2}{*}{ Age (weeks) } & \multicolumn{3}{|c|}{ Feed conversion ratio $\left(\mathrm{kg} \mathrm{kg}^{-1}\right)$} \\
\hline & $\mathrm{TM}$ & $\mathrm{CM}$ & $P$ value & & $\mathrm{TM}$ & $\mathrm{CM}$ & $P$ value \\
\hline 4 & $411 \pm 11.7$ & $403 \pm 11.3$ & 0.609 & $4-5$ & $3.15 \pm 0.29$ & $3.31 \pm 0.31$ & 0.380 \\
\hline 5 & $610 \pm 11.2$ & $589 \pm 13.2$ & 0.247 & $5-6$ & $3.59 \pm 0.25$ & $3.26 \pm 0.24$ & 0.226 \\
\hline 6 & $842 \pm 14.9$ & $832 \pm 17.1$ & 0.690 & $6-7$ & $3.80 \pm 0.22$ & $3.97 \pm 0.32$ & 0.360 \\
\hline 7 & $1109 \pm 14.3$ & $1015 \pm 19.2$ & 0.150 & $7-8$ & $4.58 \pm 0.31$ & $4.79 \pm 0.24$ & 0.336 \\
\hline 8 & $1296 \pm 18.8$ & $1252 \pm 25.7$ & 0.171 & $8-9$ & $5.10 \pm 0.30$ & $4.08 \pm 0.24$ & 0.031 \\
\hline 9 & $1536 \pm 45.9$ & $1446 \pm 27.7$ & 0.111 & $9-10$ & $5.78 \pm 0.37$ & $5.57 \pm 0.62$ & 0.410 \\
\hline 10 & $1641 \pm 29.6$ & $1667 \pm 26.6$ & 0.509 & $10-11$ & $6.16 \pm 0.45$ & $5.86 \pm 0.41$ & 0.348 \\
\hline 11 & $1768 \pm 31.6$ & $1820 \pm 32.3$ & 0.262 & $11-12$ & $5.73 \pm 0.29$ & $6.17 \pm 0.70$ & 0.325 \\
\hline 12 & $1968 \pm 29.7$ & $1884 \pm 40.1$ & 0.114 & $12-13$ & $6.35 \pm 0.37$ & $6.95 \pm 0.41$ & 0.199 \\
\hline 13 & $2125 \pm 44.9$ & $2028 \pm 32.7$ & 0.095 & $13-14$ & $5.28 \pm 0.38$ & $5.29 \pm 0.35$ & 0.499 \\
\hline 14 & $2291 \pm 46.9$ & $2166 \pm 42.5$ & 0.060 & Total mean & $4.79 \pm 0.03$ & $5.11 \pm 0.03$ & 0.000 \\
\hline
\end{tabular}

TM - group fed with feed mixture for three phases, similar to slaughter turkeys, CM - group fed with feed mixture dedicated for two phases, similar broiler chickens.

Table 3. Relative carcass, organs, and cut yields of guinea fowl in response to diets based on nutrient specifications for three- or twophased diets (mean \pm SEM).

\begin{tabular}{|c|c|c|c|}
\hline \multirow[t]{2}{*}{ Item } & \multicolumn{3}{|c|}{$\begin{array}{l}\text { Relative carcass and organ yields } \\
\text { (\% proportion of body weight) }\end{array}$} \\
\hline & TM & $\mathrm{CM}$ & $P$ value \\
\hline Slaughter weight & $2385 \pm 84.47$ & $2302 \pm 82.68$ & 0.581 \\
\hline Carcass yield & $76.64 \pm 0.93$ & $78.77 \pm 0.92$ & 0.855 \\
\hline Liver & $2.16 \pm 0.33$ & $2.30 \pm 0.25$ & 0.524 \\
\hline Heart & $0.64 \pm 0.02$ & $0.64 \pm 0.04$ & 0.160 \\
\hline Gizzard & $1.57 \pm 0.10$ & $1.65 \pm 0.10$ & 0.648 \\
\hline \multirow[t]{2}{*}{ Abdominal fat } & $2.02 \pm 0.31$ & $1.92 \pm 0.30$ & 0.632 \\
\hline & \multicolumn{3}{|c|}{$\begin{array}{c}\text { Relative cut yields } \\
\text { (\% proportion of carcass) }\end{array}$} \\
\hline Breast & $20.64 \pm 0.94$ & $21.77 \pm 0.78$ & 0.379 \\
\hline Thigh & $17.19 \pm 0.78$ & $17.63 \pm 0.45$ & 0.638 \\
\hline Drumstick & $12.19 \pm 0.37$ & $12.39 \pm 0.40$ & 0.726 \\
\hline Wings & $11.87 \pm 0.11$ & $11.67 \pm 0.15$ & 0.302 \\
\hline Trunk & $38.12 \pm 1.31$ & $36.55 \pm 1.02$ & 0.368 \\
\hline
\end{tabular}

TM - group fed with feed mixture for three phases, similar to slaughter turkeys, $\mathrm{CM}$ - group fed with feed mixture dedicated for two phases, similar to broiler chickens.

of sex on body weight was not considered, and temperatures that were standardized can be omitted; therefore, the results are in line with those of Baeza et al. (2001). However, FCR was considerably bigger in our study, by about 800 in the TM group and over $1000 \mathrm{~g}$ for guinea fowl in the CM group, which might have resulted from the lower protein content of commercial diets used.

Agwunobi and Ekpenyong (1991) considered the rearing efficiency of broiler chickens and guinea fowls after 12 weeks of rearing using the commercial diets for chickens.
The most important observation was a significantly higher survival rate of guinea fowl in comparison with chickens. They also showed by almost $50 \%$ lower feed intake along with higher FCR (4.6 vs. $3.4 \mathrm{~kg} \mathrm{~kg}^{-1}$ of body weight gain) resulting from lower final body weight $(1.4$ vs. $3.4 \mathrm{~kg})$. It seems that the results of this study can be considered similar to those quoted; however, the livability of birds included in this study amounted to $100 \%$ regardless of the group. Premavalli et al. (2013) justified the use of broiler diets in guinea fowl production due to extensively rearing of these birds and lower protein requirement in extensive rearing systems. Consequently, feed with higher nutritional value may contribute to better rearing results. Yamak et al. (2018) demonstrated a significant impact of the housing system on the body weight of meat-type guinea fowl. Greater body weight was observed in birds kept without access to runs than in a free-range system. However, this was much lower than that obtained in our study. FCR was similar to that obtained in the TM group. The degree of feed conversion largely determines the cost of rearing the birds. In guinea fowl, this ratio is quite high, exceeding $4 \mathrm{~kg} \mathrm{~kg}^{-1}$ at 14 weeks of rearing (Bernacki et al., 2012a). Similar values in intensive rearing can generate significant feeding costs, thus limiting the meat-type guinea fowl rearing on a wider scale.

The TM or CM diets used in this experiment did not affect the body weight of birds including the slaughter weight. The obtained carcass yield was similar to that shown by Ebegbulem and Asuquo (2018) for 14-week-old black and pearl guinea fowls and their crosses. Bernacki et al. (2012b) found that the color variety of birds can modify the body weight and parts' yield; considerably better values of these traits were observed in birds of the gray variety. However, the slaughter weight of guinea fowl recorded in our study at the end of the 14th week was about a kilogram higher than in the cited studies, with a much better slaughter performance (the dif- 
Table 4. Breast and thigh meat quality of guinea fowl in response to diets based on nutrient specifications for three- or two-phased diets (mean \pm SEM).

\begin{tabular}{lrrr|rrr}
\hline \multirow{2}{*}{ Item } & \multicolumn{3}{c|}{ Breast meat quality } & \multicolumn{3}{c}{ Thigh meat quality } \\
\cline { 2 - 7 } & $\mathrm{TM}$ & $\mathrm{CM}$ & $P$ value & $\mathrm{TM}$ & $\mathrm{CM}$ & $P$ value \\
\cline { 2 - 7 } & $5.61 \pm 0.19$ & $5.99 \pm 0.21$ & 0.804 & $5.94 \pm 0.13$ & $6.01 \pm 0.06$ & 0.062 \\
$\mathrm{pH}_{15}$ & $5.76 \pm 0.09$ & $5.77 \pm 0.13$ & 0.040 & $5.76 \pm 0.04$ & $5.80 \pm 0.07$ & 0.088 \\
$\mathrm{pH}_{60}$ & $5.48 \pm 0.07$ & $5.45 \pm 0.06$ & 0.852 & $5.64 \pm 0.07$ & $5.56 \pm 0.06$ & 0.414 \\
$\mathrm{pH}_{24 \mathrm{~h}}$ & $54.78 \pm 1.02$ & $54.47 \pm 0.97$ & 0.964 & $45.46 \pm 0.89$ & $45.35 \pm 0.64$ & 0.339 \\
$L^{*}$ & $3.08 \pm 0.63$ & $2.18 \pm 0.41$ & 0.161 & $10.01 \pm 0.56$ & $9.75 \pm 0.83$ & 0.447 \\
$a^{*}$ & $10.24 \pm 0.51$ & $10.26 \pm 0.56$ & 0.774 & $9.95 \pm 0.52$ & $9.33 \pm 0.42$ & 0.347 \\
$b^{*}$ & $1.55 \pm 0.22$ & $1.94 \pm 0.20$ & 0.578 & $0.72 \pm 0.22$ & $1.12 \pm 0.35$ & 0.210 \\
Natural loss (\%) & $16.95 \pm 1.56$ & $15.79 \pm 1.57$ & 0.613 & $21.08 \pm 1.92$ & $20.48 \pm 2.84$ & 0.865 \\
Cooking loss (\%) & $64.14 \pm 2.57$ & $63.22 \pm 2.65$ & 0.807 & $62.45 \pm 1.66$ & $60.83 \pm 2.47$ & 0.597 \\
Water-holding capacity $\left(\mathrm{cm}^{2}\right)$ & $14.22 \pm 1.17$ & $12.66 \pm 0.98$ & 0.467 & $19.95 \pm 1.43$ & $21.00 \pm 2.71$ & 0.373 \\
Shear force (N) & & &
\end{tabular}

TM - group fed with feed mixture for three phases, similar to slaughter turkeys, CM - group fed with feed mixture dedicated for two phases, similar to broiler chickens.

Table 5. The content of particular fatty acids in breast and thigh meat of guinea fowl in response to diets based on nutrient specifications for three- or two-phased diets (mean \pm SEM).

\begin{tabular}{|c|c|c|c|c|c|c|}
\hline \multirow[t]{2}{*}{ Item } & \multicolumn{3}{|c|}{ Breast meat } & \multicolumn{3}{|c|}{ Thigh meat } \\
\hline & $\mathrm{TM}$ & $\mathrm{CM}$ & $P$ value & $\mathrm{TM}$ & $\mathrm{CM}$ & $P$ value \\
\hline C $12: 0$ & $0.143 \pm 0.011$ & $0.167 \pm 0.015$ & 0.326 & $0.110 \pm 0.007$ & $0.130 \pm 0.004$ & 0.034 \\
\hline C $14: 0$ & $1.127 \pm 0.050$ & $1.110 \pm 0.032$ & 0.783 & $1.023 \pm 0.029$ & $1.087 \pm 0.018$ & 0.097 \\
\hline C $15: 0$ & $0.140 \pm 0.007$ & $0.143 \pm 0.009$ & 0.782 & $0.467 \pm 0.207$ & $0.137 \pm 0.002$ & 0.171 \\
\hline C $16: 0$ & $26.23 \pm 0.440$ & $25.02 \pm 0.528$ & 0.108 & $25.75 \pm 0.091$ & $25.88 \pm 0.302$ & 0.687 \\
\hline C $17: 0$ & $0.190 \pm 0.010$ & $0.187 \pm 0.011$ & 0.826 & $0.207 \pm 0.017$ & $0.213 \pm 0.015$ & 0.778 \\
\hline C $18: 0$ & $7.693 \pm 0.603$ & $8.593 \pm 0.347$ & 0.225 & $8.250 \pm 1.059$ & $9.353 \pm 0.652$ & 0.400 \\
\hline C $20: 0$ & $0.133 \pm 0.008$ & $0.167 \pm 0.015$ & 0.089 & $0.123 \pm 0.009$ & $0.147 \pm 0.012$ & 0.149 \\
\hline C 22:0 & $0.130 \pm 0.020$ & $0.170 \pm 0.029$ & 0.275 & $0.117 \pm 0.030$ & $0.157 \pm 0.028$ & 0.346 \\
\hline C $24: 0$ & $0.100 \pm 0.000$ & $0.110 \pm 0.000$ & $\operatorname{tr}$ & $0.060 \pm 0.000$ & $0.045 \pm 0.009$ & 0.312 \\
\hline C $14: 1 \mathrm{n} 5$ & $0.340 \pm 0.055$ & $0.287 \pm 0.018$ & 0.388 & $0.317 \pm 0.061$ & $0.273 \pm 0.026$ & 0.538 \\
\hline C $16: 1 \mathrm{n} 7$ & $5.663 \pm 0.739$ & $4.747 \pm 0.303$ & 0.291 & $5.963 \pm 0.923$ & $5.093 \pm 0.464$ & 0.419 \\
\hline C $17: 1 \mathrm{n} 7$ & $0.130 \pm 0.010$ & $0.093 \pm 0.012$ & 0.037 & $0.147 \pm 0.012$ & $0.143 \pm 0.008$ & 0.816 \\
\hline C $18: 1$ & $30.44 \pm 1.014$ & $30.50 \pm 1.191$ & 0.973 & $30.08 \pm 0.801$ & $30.11 \pm 0.909$ & 0.981 \\
\hline C $20: 1$ & $0.540 \pm 0.029$ & $0.577 \pm 0.046$ & 0.515 & $0.473 \pm 0.040$ & $0.507 \pm 0.019$ & 0.475 \\
\hline C $22: 1$ n9 & tr & $\operatorname{tr}$ & tr & $0.070 \pm 0.000$ & $\operatorname{tr}$ & $\operatorname{tr}$ \\
\hline C 18: 2 n6 (LA) & $21.87 \pm 0.433$ & $22.46 \pm 0.617$ & 0.452 & $22.97 \pm 0.207$ & $22.37 \pm 0.448$ & 0.263 \\
\hline C $18: 3$ n6 (GLA) & $0.123 \pm 0.008$ & $0.100 \pm 0.004$ & 0.040 & $0.143 \pm 0.020$ & $0.110 \pm 0.010$ & 0.178 \\
\hline C $18: 3$ n 3 (ALA) & $1.060 \pm 0.015$ & $0.953 \pm 0.040$ & 0.032 & $1.080 \pm 0.080$ & $0.963 \pm 0.053$ & 0.250 \\
\hline C $20: 2 \mathrm{n} 6$ & $0.680 \pm 0.158$ & $0.887 \pm 0.265$ & 0.130 & $0.427 \pm 0.035$ & $0.427 \pm 0.035$ & 1.000 \\
\hline C $20: 3 \mathrm{n} 6$ & $0.230 \pm 0.044$ & $0.253 \pm 0.056$ & 0.750 & $0.237 \pm 0.008$ & $0.237 \pm 0.018$ & 1.000 \\
\hline C $20: 4$ n6 (AA) & $2.680 \pm 0.802$ & $3.117 \pm 0.846$ & 0.716 & $2.017 \pm 0.346$ & $2.180 \pm 0.398$ & 0.763 \\
\hline C $20: 5 \mathrm{n} 3$ & $0.130 \pm 0.000$ & $0.160 \pm 0.000$ & $\operatorname{tr}$ & $0.055 \pm 0.003$ & $0.055 \pm 0.003$ & 1.000 \\
\hline C $22: 2$ n6 & $0.180 \pm 0.000$ & $0.360 \pm 0.000$ & $\operatorname{tr}$ & $0.180 \pm 0.035$ & $0.123 \pm 0.021$ & 0.172 \\
\hline C $22: 6$ n3 (DHA) & $0.253 \pm 0.076$ & $0.270 \pm 0.093$ & 0.561 & $0.220 \pm 0.020$ & $0.157 \pm 0.022$ & 0.061 \\
\hline
\end{tabular}

TM - group fed with feed mixture for three phases, similar to slaughter turkeys, CM - group fed with feed mixture dedicated for two phases, similar to broiler chickens, $\mathrm{tr}$ - trace (content lower than 0.05\%); C14:0 - myristic acid, C15:0 - pentadecylic acid, C16:0 - palmitic acid, C17:0 - margaric acid, C18:0 - stearic acid, C20:0 - arachidic acid, C22:0 - behenic acid, C24:0 - lignoceric acid, C14: 1 - tetradecenoic acid, C16:1 - palmitoleic acid, C17:1 - heptadecenoic acid, C18:1 - oleic acid, C20:1-gondoic acid, C22:1-nervonic acid, C18:2 n6 - linoleic acid (LA), C18:3 n6 - $\gamma$-linolenic acid (GLA), C18:3n $3-\alpha$-linolenic acid (ALA), C20: 2 n6 - eicosadienoic acid, C20:3 n6 - dihomo- $\gamma$-linolenic, C20:4 n6 - arachidonic acid (AA), C20:5 n3 - eicosapentaenoic acid, C22:2 n6 - docosadienoic acid, C22: 6 $\mathrm{n} 3$ - docosahexaenoic acid (DHA). 
Table 6. Fatty acid profile in breast and thigh meat of guinea fowl in response to diets based on nutrient specifications for turkeys and broilers $($ Mean \pm SEM).

\begin{tabular}{lrrr|rrr}
\hline Item & \multicolumn{3}{c|}{ Breast meat } & \multicolumn{3}{c}{ Thigh meat } \\
\cline { 2 - 7 } & TM & CM & $P$ value & TM & CM & $P$ value \\
\hline SFA & $35.80 \pm 0.17$ & $35.53 \pm 0.19$ & 0.304 & $35.72 \pm 1.01$ & $37.13 \pm 0.49$ & 0.248 \\
MUFA & $37.10 \pm 1.59$ & $36.19 \pm 1.26$ & 0.662 & $37.02 \pm 1.52$ & $36.13 \pm 1.24$ & 0.661 \\
PUFA & $26.98 \pm 1.48$ & $28.19 \pm 1.40$ & 0.564 & $27.14 \pm 0.53$ & $26.60 \pm 0.86$ & 0.599 \\
n3 & $1.35 \pm 0.09$ & $1.27 \pm 0.09$ & 0.524 & $1.34 \pm 0.07$ & $1.15 \pm 0.03$ & 0.059 \\
n6 & $25.63 \pm 1.39$ & $26.93 \pm 1.34$ & 0.516 & $25.81 \pm 0.60$ & $25.44 \pm 0.86$ & 0.735 \\
n9 & $30.75 \pm 1.00$ & $30.83 \pm 1.19$ & 0.962 & $30.42 \pm 0.77$ & $30.45 \pm 0.89$ & 0.978 \\
n6/n3 ratio & $19.01 \pm 0.22$ & $21.46 \pm 1.16$ & 0.066 & $19.79 \pm 1.71$ & $22.13 \pm 0.95$ & 0.258 \\
PUFA / SFA ratio & $0.75 \pm 0.04$ & $0.79 \pm 0.04$ & 0.484 & $0.76 \pm 0.01$ & $0.72 \pm 0.02$ & 0.057 \\
PI & $39.37 \pm 4.54$ & $53.15 \pm 4.03$ & 0.161 & $37.41 \pm 1.42$ & $36.89 \pm 2.04$ & 0.837 \\
AI & $0.48 \pm 0.01$ & $0.46 \pm 0.01$ & 0.161 & $0.47 \pm 0.00$ & $0.48 \pm 0.00$ & 0.020 \\
TI & $0.99 \pm 0.01$ & $0.98 \pm 0.01$ & 0.659 & $0.99 \pm 0.05$ & $1.06 \pm 0.02$ & 0.225 \\
DFA & $71.78 \pm 0.47$ & $72.98 \pm 0.52$ & 0.118 & $72.41 \pm 0.14$ & $72.08 \pm 0.68$ & 0.292 \\
HFSA & $27.50 \pm 0.50$ & $26.29 \pm 0.55$ & 0.133 & $26.88 \pm 0.31$ & $27.10 \pm 0.77$ & 0.535 \\
h/H & $2.02 \pm 0.00$ & $2.10 \pm 0.00$ & 0.955 & $2.00 \pm 0.01$ & $1.97 \pm 0.04$ & 0.424 \\
\hline
\end{tabular}

TM - group fed with feed mixture for three phases, similar to slaughter turkeys, CM - group fed with feed mixture dedicated for two phases, similar to broiler chickens, SFA - saturated fatty acid, PUFA - polyunsaturated fatty acid, MUFA - monounsaturated fatty acid, $\mathrm{PI}$ - peroxidation index, AI - atherogenic index, TI - thrombogenic index, DFA - desirable fatty acid, HFSA - hypercholesterolemic saturated fatty acid, h / $\mathrm{H}$ - hypocholesterolemic / hypercholesterolemic ratio.

ference amounted to $8 \%$ ) but with a lower yield of pectoral muscle in carcasses $(6 \%)$. Similar comparison was seen between the results of our study and those of Kokoszynski et al. (2011). Body weight and slaughter performance were much lower, whereas breast yield exceeded $23 \%$. An extremely high yield of pectoral muscles (about $30 \%$ ) in the carcasses of guinea fowl kept in Sudan was recorded by Eltayeb et al. (2015), but they indicated that the diversity of both production and slaughter performance parameters including the weight of giblets is even due to the flock location within a single country, which is probably associated with different thermal conditions. Teye et al. (2001), while comparing the slaughter parameters of guinea fowl of different origins (imported and local to Ghana), found that imported birds had a higher body weight and carcass yield than the local variety in addition to higher edible giblet yields. It is noteworthy that relative gizzard weight to that of carcass was $\approx 8 \%$ in our studies; after conversion, the relative gizzard yield was about $2 \%$. It probably resulted from the contribution of green fodder in the feeding (Batkowska et al., 2015).

It is well known that the animal diet is a key factor in determining the quality of meat. Quantifiable properties of meat such as water-holding capacity, shear force, drip loss, cooking loss, $\mathrm{pH}$, and color are indispensable for processors to acquire functional properties that will ensure a final product characterized by a quality acceptable to the consumers (Cheng and Sun, 2008). Water-holding capacity of fresh meat is an important quality attribute since it affects major characteristics of the cooked meat such as technological and eating quality. Drip loss as a result of postmortem myofibril shortening is caused by $\mathrm{pH}$ fall, denaturation of myosin, and the formation of actomyosin at the onset of rigor mortis. Any loss of water or shrinkage due to loss of water hints at a less optimal quality. Excessive shrinkage can have an adverse effect on appearance, juiciness, and tenderness (Bertram et al., 2000). Among many other factors, feeding of animals affects the ability of the animal muscles to retain water (Cheng and Sun, 2008). However, the current study did not show a significant effect of feeding on the water-holding capacity of breast and thigh muscles of meat-type guinea fowls. Among the feeding strategies that have the potential to improve the ability of the animal muscles to retain water, the supplementation of vitamin $\mathrm{E}$ or $\mathrm{D}_{3}$ has its influence on drip loss. In present study, although the composition of the mixtures differed in the content of these minerals, this did not affect the water-holding capacity, drip loss, or cooking loss of muscles. Another important factor that affects meat quality and determines consumer preferences is the meat color. Lightness $\left(L^{*}\right)$ values in the present study ranged between 45.35 and 45.46 for thigh muscle and between 54.47 and 54.78 for breast muscle and were lower than the values that were reported in a previous study (Sarica et al., 2019). In contrast, other researchers obtained lower $L^{*}$ values for guinea fowl muscles (Kokoszyński et al., 2011). Redness $\left(a^{*}\right)$ values in the present study ranged between 2.18 and 3.08 for breast muscle and between 9.75 and 10.01 for thigh muscle. The values obtained are lower for the thigh muscles and higher for the breast muscles compared to those obtained by Sarica et al. (2019).

Few studies have been published on the quality of guinea fowl meat. To the best of our knowledge, we are the first to investigate the effect of feeding commercial diets to guinea 
fowl during dedicated different phases of growth on the physicochemical properties of meat. Laudadio et al. (2012) substituted soybeans with peas in the diet of guinea fowl raised for 12 weeks. Despite a slightly lower percentage of protein in the diet compared to current study, the birds achieved a similar body weight, while it was found that the breast muscles were characterized by lower $L^{*}$ parameters, indicating the lightness of muscles. The values of $\mathrm{pH}$ and drip loss of muscle were similar to those obtained in this experiment; however, the muscles showed a lower water-holding capacity value compared to our results. Higher water-holding capacity values of more than $10 \%$ were observed for the thigh muscles. Water-holding capacity of the breast muscle was similar to that presented by Kokoszyński et al. (2011), whereas it was higher in the case of thigh muscles than in the cited studies. The research showed that the share of the abdominal fat was 4 times lower than that in the authors' own research, despite a slightly longer rearing (16 weeks). This could indicate a greater amount of intramuscular fat and therefore a greater water-holding capacity. It is particularly interesting because the fatty content of the carcass is linked to the intestinal fat content. Significantly higher water-holding capacity values were recorded in the studies by Sarica et al. (2019), regardless of the breeding system or age of guinea fowl; their muscles, regardless of the type, also lost more water due to natural loss and loss after thermal treatment compared to the muscles of the birds in this study. Musundire et al. (2017) analyzed the influence of age and gender on body weight, carcass characteristics, and physical and chemical properties of breast muscles of chickens and free-range guinea fowl. They found that guinea fowls had a higher body and carcass weight, as well as the breast muscle weight compared to chickens. The cooking loss was greater in guinea fowl, males, and younger (growing) birds than in chickens, female, and adult birds.

The fatty acid profile of breast muscles obtained in our study considerably differs from that presented by Tufarelli et al. (2015). They studied the effects of dietary substitution of soybean meal with micronized-dehulled white lupin in meattype guinea fowl on meat fatty acid composition. Authors showed lower concentration of saturated (SFA) and higher of unsaturated fatty acids (MUFA and PUFA) in breast muscles compared to our findings. Studies carried out by Chiroque et al. (2018) showed considerably lower $n 6 / n 3$ values for guinea fowl muscles fed diet having $18.5 \%$ protein compared to our results. Similarly, the content of fatty acids demonstrated in the study performed by Laudadio et al. (2012) was different from that in our study. The content of ALA and DHA in muscles from guinea fowl fed micronizeddehulled pea was higher, while GLA content was almost 2 times lower. Differences may arise from many factors including various ingredients used in the feed or the age of birds. According to Hoffman and Tlhong (2012), the differences may result from the analysis conditions. The quoted study showed a lower content of SFA, higher unsaturated fatty acid (UFA), and greater SFA / UFA ratio than in the current study. The reasons for this may be differences in rearing conditions and the availability of green fodder for birds (they came from small-scale farms). As indicated by Dal Bosco et al. (2016), the share of green fodder in poultry nutrition may modify the fatty acid profile in meat.

A similar proportion of SFA content in the breast muscle of guinea fowls was found by Bernacki et al. (2012b). Their study also showed a higher content of PUFA and a lower content of MUFA. There was a greater percentage of ALA and a lower concentration of DHA. The birds were fed balanced diets for broiler chickens and kept under controlled environmental conditions. It is important to find the differences in the chemical composition of meat, including to some extent the profile of fatty acids due to the color variety of guinea fowls.

An analysis of the available literature indicates significant variability of traits within the species Numida meleagris. It results from color variety, growth rate, sex, age, husbandry system, diet, and climatic conditions. Therefore, the problem of the lack of possibility to generalize the obtained research results often arises. Nevertheless, despite their much lower popularity than the typical meat-type poultry species, such as chickens or turkeys, guinea fowls have a great potential not only in terms of the quantity and quality of meat obtained but also as research material, and their advantages in this respect are worth propagating.

\section{Conclusion}

The presented results confirm the thesis related to the benefits of feeding meat-type guinea fowl with commercially available diets for other meat-type poultry species. Irrespective of the diet, comparable values were obtained among others in terms of the body weight and slaughter performance. Various protein content in both diets did not influence the above-mentioned features. A detailed analysis of technological traits of the pectoral and thigh muscles indicates that a similar quality of the final product was obtained, which may indicate the universality of commercially available diets in the market for rearing the meat-type guinea fowl without any loss of production. The difference in favor of TM diet, with a higher protein content, concerned the feed conversion ratio, but for economic reasons (lower protein diets are cheaper) it seems more advantageous to feed guinea fowl with CM diets.

Data availability. Data used and analyzed during this study are available from the corresponding author upon reasonable request.

Author contributions. All authors contributed to the work described in the paper. KD and JB designed the experiment and performed it on the farm. MK, UA, and IR assessed the meat quality; AA and BH performed chemical analyses. JB analyzed data statis- 
tically. JB, MK, and KD wrote the paper; UA and BH corrected the manuscript during the editorial process. All authors read and approved the final paper.

Competing interests. The authors declare that they have no conflict of interest.

Disclaimer. Publisher's note: Copernicus Publications remains neutral with regard to jurisdictional claims in published maps and institutional affiliations.

Review statement. This paper was edited by Manfred Mielenz and reviewed by two anonymous referees.

\section{References}

Agbolosu, A. A., Ahunu, B. K., Kayang, B. B., Aboagye, G. S., and Naazie, A.: Variation in some qualitative traits of the indigenous guinea fowls in northern Ghana, in: Proceedings of intensification of domestic animal production through modern techniques: the role of the youth, Ghana Animal Science Association, Tamale, Ghana, 246-252, 2014.

Agwunobi, L. and Ekpenyong, T.: Nutritive and economic value of guinea-fowl (Numida-meleagris) production in developing-countries, J. Sci. Food Agr., 52, 301-308, https://doi.org/10.1002/jsfa.2740520303, 1990.

Alkan, S., Karsli, T., Galic, A., and Karabag, K.: Determination of phenotypic correlations between internal and external quality traits of guinea fowl eggs, Kafkas Univ. Vet. Fak., 19, 861-867, https://doi.org/10.9775/kvfd.2013.8988, 2013.

Arakawa, K. and Sagai, M.: Species-differences in lipid peroxide levels in lung-tissue and investigation of their determining factors, Lipids, 21, 769-775, https://doi.org/10.1007/BF02535410, 1986.

Ayorinde, K. L.: Guinea fowl (Numida-Meleagris) as a proteinsupplement in Nigeria, World Poultry Sci. J., 47, 21-26, https://doi.org/10.1079/WPS19910003, 1991.

Baeza, E., Juin, H., Rebours, G., Constantin, P., Marche, G., and Leterrier, C.: Effect of genotype, sex and rearing temperature on carcase and meat quality of guinea fowl, Brit. Poultry Sci., 42, 470-476, https://doi.org/10.1080/00071660120070640, 2001.

Bashir, L., Ossai, P. C., Shittu, O. K., Abubakar, A. N., and Caleb, T.: Comparison of the nutritional value of egg yolk and egg albumin from domestic chicken, guinea fowl and hybrid chicken, J. Exp. Agric. Int., 6, 310-316, https://doi.org/10.9734/AJEA/2015/15068, 2015.

Batkowska, J., Brodacki, A., Ziȩba, G., Horbańczuk, J. O., and Łukaszewicz, M.: Growth performance, carcass traits and physical properties of chicken meat as affected by genotype and production system, Arch. Anim. Breed., 58, 325-333, https://doi.org/10.5194/aab-58-325-2015, 2015.

Bernacki, Z., Bawej, M., and Kokoszynski, D.: Carcass composition and breast muscle microstructure in guinea fowl (Numida meleagris L.) of different origin, Folia Biologica (Kraków), 60, 175-179, https://doi.org/10.3409/fb60_3-4.175-179, 2012a.
Bernacki, Z., Bawej, M., and Kokoszynski, D.: Quality of meat from two guinea fowl (Numida meleagris) varieties, Arch. Geflügelkd., 76, 203-207, 2012b.

Bertram, H. C, Petersen, J. S., and Andersen, H. J.: Relationship between $\mathrm{RN}$ - genotype and drip loss in meat from Danish pigs, Meat Sci., 56, 49-55, https://doi.org/10.1016/S03091740(00)00018-8, 2000.

Cheng, Q. and Sun, D. W.: Factors affecting the water holding capacity of red meat products: A review of recent research advances, Crit. Rev. Food Sci., 48, 137-159, https://doi.org/10.1080/10408390601177647, 2008.

Chiroque, G., Vasquez, G., Vasquez, E., Mas, D., Betancur, C., Ruiz, C., Botello, A., and Martinez, Y.: Growth performance, carcass traits and breast meat fatty acids profile of helmeted guinea fowls (Numida meleagris) fed increasing level of linseed (Linum usitatissimum) and pumpkin seed (Cucurbita moschata) meals, Revista Brasileira de Ciência Avícola, 20, 665-674, https://doi.org/10.1590/1806-9061-2018-0760, 2018.

Clydesdale, F. M.: Instumental techniques for color measurement of foods, Food Technol.-Chicago 10, 52-59, 1976.

Commision Internationale de l'Eclairage: Recommendations on uniform colour spaces, colour difference equations, psychometric color terms, Supplement no. 2, Bureal Central de la CIE, Paris, 1978.

Council of the European Union: Council Regulation (EC) No $1099 / 2009$ of 24 September 2009 on the protection of animals at the time of killing, OJL, 303, 1-30, 2009.

Dal Bosco, A., Mugnai, C., Mattioli, S., Rosati, A., Ruggeri, S., Ranucci, D., and Castellini C.: Transfer of bioactive compounds from pasture to meat in organic free-range chickens, Poultry Sci., 95, 2464-2471, https://doi.org/10.3382/ps/pev383, 2016.

Domaradzki, P., Florek, M., Skalecki, P., Litwnczuk, A., Kedzierska-Matysek, M., Wolanciuk, A., and Tajchman, K.: Fatty acid composition, cholesterol content and lipid oxidation indices of intramuscular fat from skeletal muscles of beaver (Castor fiber L.), Meat Sci., 150, 131-140, https://doi.org/10.1016/j.meatsci.2018.12.005, 2019.

Ebegbulem, V. N. and Asuquo, B. O.: Growth performance and carcass characteristics of the black and pearl guinea fowl (Numida meleagris) and their crosses, Global Journal of Pure and Applied Sciences, 24, 11-16, https://doi.org/10.4314/gjpas.v24i1.2, 2018.

Eltayeb, N. M., Yousif, I. A., Elamin, K. M., and Hamid, M. A.: Determination of growth performance and carcass characteristics of Sudanese guinea fowl (Numida Meleagris) in different location, Journal of Animal Science Advances, 5, 1473-1479, https://doi.org/10.5455/jasa.20151118111140, 2015.

European Parliament and the Council of the European Union: Directive 2010/63/EU of the European Parliament and of the Council of 22 September 2010 on the protection of animals used for scientific purposes. OJL, 276, 33-79, 2010.

Grau, R. and Hamm, R.: Eine einfache Method zur Bestimmung der Wasserbindung im Muskel, Naturwissenschaften, 40, 29-30, 1953.

Gwaza, D. S and Elkanah, H.: Assessment of external egg characteristics and production indices of the dual purpose French guinea fowl under semiarid conditions in Nigeria, J. Res. Rep. Genet., 1, 13-17, 2017. 
Hahn, G. and Spindler, M.: Method of dissection of turkey carcases, World Poultry Sci. J., 58, 179-197, https://doi.org/10.1079/WPS20020017, 2002.

Hoffman, L. C. and Tlhong, T. M.: Proximate and fatty acid composition and cholesterol content of different cuts of guinea fowl meat as affected by cooking method, J. Sci. Food Agr., 92, 25872593,https://doi.org/10.1002/jsfa.5682, 2012.

IBM Corp.: SPSS Statistics for Windows, Version 24.0, IBM Corp., Armonk, NY, 2016.

Khairunnesa, M., Das, S. C., and Khatun, A.: Hatching and growth performances of guinea fowlunder intensive management system, Progressive Agriculture, 27, 70-77, https://doi.org/10.3329/pa.v27i1.27544, 2016.

Kokoszyński, D., Bernacki, Z., Korytkowska, H., Wilkanowska, A., and Piotrowska, K.: Effect of age and sex on slaughter value of guinea fowl (Numida meleagris), Journal of Central European Agriculture, 12, 255-266, https://doi.org/10.5513/JCEA01/12.2.907, 2011.

Kyere, C. G., Poku, P. A. J., Twumasi, G., Korankye, O., Seidu, H., and Poku, P. A. S.: Effect of vitamin c supplementation on egg quality, carcass characteristics and sensory properties of meat of the pearl guinea fowl (Numida meleagris) in Ghana, Asian Journal of Research in Animal and Veterinary Sciences, 5, 38-45, 2020.

Laudadio, V., Nahashon, S. N., and Tufarelli, V.: Growth performance and carcass characteristics of guinea fowl broilers fed micronized-dehulled pea (Pisum sativum L.) as a substitute for soybean meal, Poultry Sci., 91, 2988-2996, https://doi.org/10.3382/ps.2012-02473, 2012.

Lundstrom, K. and Malmfors, G.: Variation in light-scattering and water-holding capacity along the porcine longissimus-dorsi muscle, Meat Sci., 15, 203-214, https://doi.org/10.1016/03091740(85)90076-2, 1985.

Medeiros, E., Queiroga, R., Oliveira, M., Medeiros, A., Sabedot, M., Bomfim, M., and Madruga, M.: Fatty acid profile of cheese from dairy goats fed a diet enriched with castor, sesame and faveleira vegetable oils, Molecules 19, 992-1003, https://doi.org/10.3390/molecules19010992, 2014.

Moreki, J. C. and Seabo, D.: Guinea fowl production in Botswana, Journal of World's Poultry Research JWPR, 2, 1-4, 2012.

Musundire, M. T., Halimani, T. E., and Chimonyo, M.: Physical and chemical properties of meat from scavenging chickens and helmeted guinea fowls in response to age and sex, Brit. Poultry Sci., 58, 390-396, https://doi.org/10.1080/00071668.2017.1313961, 2017.

Nahashon, S. N., Aggrey, S. E., Adefope, N. A., and Amenyenu, A.: Modeling growth characteristics of meat-type guinea fowl, Poult. Sci., 85, 943-946, https://doi.org/10.1093/ps/85.5.943, 2006.

Obike, O. M., Oke, U. K., and Azu, K. E.: Comparison of egg production performance and egg quality traits of pearl and black strains of guinea fowl in a humid rain-forest zone of Nigeria, International Journal of Poultry Science, 10, 547-551, 2011.

Onunkwo, D. N. and Okoro, I. C.: External and internal egg quality characteristics of three varieties of helmeted guinea fowl $\mathrm{CNu}$ mida meleagris) in Nigeria, International Journal of Current Research and Review, 7, 10-17, 2015.

Panyako, P. M., Imboma, T., Kariuki, D. W., Makanda, M., Oyier, P. A., Malaki, P., Ndiem, E. K., Obanda, V., Agwanda, B., Ngeiywa, K. J., and Lichoti, J.: Phenotypic characterization of domesticated and wild helmeted Guinea fowl of Kenya, Livestock Research for Rural Development, 28, 158, available at: http://lrrd.cipav.org.co/lrrd28/9/omme28158.html (last access: 15 July 2021), 2016.

Polish Committee for Standardization: PN-EN ISO 5508:1996 Animal and vegetable fats and oils - analysis by gas chromatography of methyl esters of fatty acids, Polish Committee for Standardization, Warsaw, Poland, 1996.

Polish Committee for Standardization: PN-EN ISO 5509:2001: Animal and vegetable fats and oils - Preparation of methyl esters of fatty acids, Polish Committee for Standardization, Warsaw, Poland, 2001.

Premavalli, K., Ashok, A., Omprakash, A. V., Sangilimadan, K., and Ramanujam, R.: Influence of broiler starter and finisher rations on the growth performance of Guinea fowl keets, Indian Vet. J., 90, 39-40, 2013.

Renna, M., Cornale, P., Lussiana, C., Malfatto, V., Mimosi, A., and Battaglini, L. M.: Fatty acid profile of milk from goats fed diets with different levels of conserved and fresh forages, Int. J. Dairy Technol., 65, 201-207, https://doi.org/10.1111/j.14710307.2011.00754.x, 2012.

Sarica, M., Boz, M. A., Yamak, U. S., and Ucar, A.: Effect of production system and slaughter age on some production traits of guinea fowl: Meat quality and digestive traits, S. Afr. J. Anim. Sci., 49, 192-199, https://doi.org/10.4314/sajas.v49i1.22, 2019.

Teye, G. A., Gyawu, P., and Agbolosu, A. A.: Growth potential and carcass yields of exotic and indigenous Guinea fowls in Ghana, Development Spectrum, an Interfaculty, Journal of the University of Development Studies, Tamale, Ghana, 1, 34-40, 2001.

Tufarelli, V., Demauro, R., and Laudadio, V.: Dietary micronizeddehulled white lupin (Lupinus albus L.) in meat-type guinea fowls and its influence on growth performance, carcass traits and meat lipid profile, Poultry Sci., 94, 2388-2394, https://doi.org/10.3382/ps/pev218, 2015.

Ulbricht, T. L. V and Southgate, D. A. T.: Coronary heart-disease - 7 dietary factors, Lancet, 338, 985-992, https://doi.org/10.1016/0140-6736(91)91846-M, 1991.

Wallace, P. A., Nyameasem, J. K., Aboagye, G. A., AffedzieObresi, S., Nkegbe, K., Murray, F., Botchway, V., Karbo, N., Leschen, W., Maquart, P. O., and Clottey, V.: Effects of replacing fishmeal with black soldier fly larval meal in the diets of grower-finishing guinea fowls reared under tropical conditions, Trop. Anim. Health Pro., 50, 1499-1507, https://doi.org/10.1007/s11250-018-1588-5, 2018.

Yamak, U. S., Sarica, M., Boz, M. A. and Ucar, A.: Effect of production system (barn and free range) and slaughter age on some production traits of guinea fowl, Poultry Sci., 97, 47-53, https://doi.org/10.3382/ps/pex265, 2018.

Yang, H. S., Moon, S. S., Jeong, J. Y, Choi, S. G, Joo, S. T., and Park, G. B.: Effect of sodium bicarbonate injection in pre-rigor porcine M-Longissimus lumborum on pork quality, Asian-Austral. J. Anim., 19, 898-904, https://doi.org/10.5713/ajas.2006.898, 2006.

Yildirim, A.: Nutrition of guinea fowl breeders: A review, Journal of Animal Science Advances, 2, 188-193, 2012. 